\title{
The Demise of the Journal Ranking: A Victory for Common Sense
}

Goran Runeson (University of Technology, Sydney Australia)

In a Ministerial statement to the Senate Economics Legislation Committee: Improvements to Excellence in Research for Australia (ERA), the Minister for Innovation, Industry, Science and Research, Senator Kim Carr, in a brilliant example of creative writing, has pronounced the 2010 ERA an outstanding success, with a small exception, the quality ranking of journals. The ARC has advised the Minister that consultations had revealed that there is a "widespread preference for limited change": the "refinement of the journal quality indicator" by the removal of the "prescriptive $A^{*}, A, B$ and $C$ ranks"; something no doubt made less painful as "the rankings were inherited from the discontinued Research Quality Framework (RQF) process of the previous government" and therefore not really needed.

One of the reasons for the change of mind was that "There is clear and consistent evidence that the rankings were being deployed inappropriately within some quarters of the sector, in ways that could produce harmful outcomes, and based on a poor understanding of the actual role of the rankings. One common example was the setting of targets for publication in $A$ and $A^{*}$ journals by institutional research managers." There were obviously a lot of naughty people who should have understood that actually using the ranking in the most obvious way was a 'no-no', and that leaves the question: what was the aim of the ranking if this was inappropriate.

There were problems other than the "inappropriate" use of the rankings. The rankings themselves were carried out in secrecy and with very limited resources and support, given the magnitude of the job - some 55000 journals ranked by less than 200 people. When things went wrong, and there were more than 7000 submissions to ARC during the consultation period indicating that they did, frequently, there was, as Ross Thomas, editor of the Journal of Educational Administration, points out, no process by which the mistakes could be corrected. "Numerous attempts to have ERA's palpably incorrect ranking reconsidered were rejected and met with a standard, platitudinous response: there were many academies and individuals involved in the ranking process; ARC personnel were satisfied with the procedures followed and, submissions would be noted for when next ERA embarked on the exercise. Many were advised that ERA had defensible evidence (presumably) justifying its treatment of the journal. The reply to a freedom of information request to view this defensible evidence was farcical - blank pages and others with a few heavily censored (and irrelevant) paragraphs."

In the case of Construction Management, among several other irregularities, including a distorted perception of Open Access journals by at least one senior member of the ranking committee who arbitrarily decided and enforced that no Open Access journal would be given an $A$ ranking despite the fact that there were numerous examples of $A^{*}$ and $A$ rankings of such journals in other disciplines. This was an ultimate triumph of form over content and obviously, it is a reasonable conclusion that AJCEB suffered from this misconception. The discontinuation of the ranking, has now partially corrected the situation. The problem that does remain, though, for journals such as AJCEB is: How long will it take to undo the damage done by the ranking and how long will it take until the actual quality of the journal takes precedence over the now defunct ranking. There is no doubt that the ranking did distort the submission of papers and while the journal has been exceptionally well supported 
in Australia, there has been a - hopefully temporary - change in the supply of papers from some areas where the rankings have been used "inappropriately".

The consequences are discussed rather light-heartedly by Joseph Gora, in a scene from the beleaguered ARC bunker just before the capitulation: The actors are disguised as the Minister, Senator Carr and the ARC CEO Professor Shiel

ARC General Sheil: But there's more, Field Marshal. We may be accused of war crimes.

Field Marshal Carr: You what?! Like what, for Christ's sake?

ARC General Sheil: The accusations are out there, sir: a massive waste of time and money, sullying the reputation of countless journals, closure of others, screwing up university recruitment and promotion processes, influencing the entire culture of scholarship and publications, undermining Australian journals, changing rankings without any reasons being given, excessive secrecy over the ranking process ... that sort of thing.

Maybe, it isn't all that light-hearted if you think of the consequences but you can enjoy the whole story in http://www.theaustralian.com.au/higher-education/opinion-analysis/inside-theera-bunker/story-e6frgcko-1226071198170 The minister's statement is available at: http://minister.innovation.gov.au/carr/mediareleases/pages/improvementstoexcellenceinrese archforaustralia.aspx and Professor Ross Thomas can be found at: http://www.theaustralian.com.au/higher-education/rankings-gone-but-what-about-thestench/story-e6frgcjx-1226071074342au/higher-education/rankings-gone-but-what-aboutthe-stench/story-e6frgcjx-1226071074342 